\title{
И.Н. Трошкина
}

\section{ДИНАМИКА ЦЕННОСТНЫХ ОРИЕНТАЦИЙ И ТИПОВ СЕМЬИ (НА ПРИМЕРЕ ХАКАССКОГО ЭТНОСА)}

\author{
Исследование выявило ценностные предпочтения этносообщества и типь семьи \\ в разные исторические периоды. Раскрыты основы трансформационных процессов \\ хакасской семьи через призму динамики культурных основ этноса. \\ Ключевые слова: иенностные ориентации, типология хакасской семьи.
}

Изучение проблематики ценностных ориентаций впервые представлено в отечественной науке в русле философского направления В.П. Тугариновым (в философии) [1]; О.Г. Дробницким (в этике) [2]; А.А. Ивиным (в логике) [3]. В отечественной научной литературе наиболее разработанным считается марксистский подход, другим только положено основание. Различия заключаются в определении природы ценностей. В рамках данного направления имеются работы Е.А. Подольской, А.М. Коршунова, М.В. Демина, В.Л. Оссовского, В. Брожика и др. Второй подход рассматривает ценность как образование сознания в форме обобщенных представлений и предпочитаемых благ. Яркими представителями данного направления являются В.Б. Моин, И.С. Нарский, О.М. Бакурадзе, В.П. Розин, И.М. Попова, А.Г. Здравомыслов и др. Несогласованность подходов привела к формированию неразрешенных проблем: природа ценностей, соотношение общественных и личных ценностей, структура, существование общечеловеческих ценностей, классификация.

Проблема семейных ценностей/ценностных ориентаций рассматривалась в работах Т.В. Свадьбиной, О.В. Бессчетновой, Т.П. Оксенченко, Л.И. Савиновой и др. Наиболее разработанными считаются вопросы: полоролевых ценностей в семье (И.В. Бестужев-Лада, М.Ю. Арутюнян, О.М. Здравомыслова, 3.А. Янкова и др.); семейно-родовых ценностей (М.Г. Панкратова, И.С. Кон, Т.А. Гурко, Л.Г. Сологуб, Ю.А. Гаспарян и др.); ценностей супружества (М.С. Мацковский, В.Т. Лисовский, Т.Г. Поспелова, И.С. Голод, И.С. Кон и проч.); семейно-родительских ценностей (А.И. Антонов, В.М. Медков, Т.А. Гурко, И.Г. Ивченко, В.В. Бойко, О.Г. Исупова, Г.Г. Филиппова и др.).

В целом, несмотря на актуальность исследований по ценностям и ценностным ориентациям семьи, их следует признать недостаточно разработанными. Несмотря на раскрытие отдельных проблем, не устранен некоторый «разрыв» между философскими основаниями и опирающимися на фактические научные данные наработками.

Ценностная проблематика переплетается с проблемой типологии семьи. В отечественной литературе изначально это направление представлено историческим и экономическим блоками, где в большинстве случаев 
используется общая структура классификации, основанная на количестве и структуре семей.

В современный период разработка данного проблемного поля проходит в русле социологической концепции М.С. Мацковского и его последователей [4]. Его типология основана на уровне доходов семей. Тема является мало разработанной.

Существующие в истории общества формы мировоззрения - мифологическое, религиозное, идеологическое и устанавливающееся ценностное сознание [5] - влекут за собой смену ценностно-мировоззренческих приоритетов относительно института семьи (табл. 1).

Таблииа 1

Соответствие форм мировоззрений и основных приоритетов хакасского общества

Correspondence of worldview forms and the main priorities of the khakass society

\begin{tabular}{|l|c|}
\hline \multicolumn{1}{|c|}{$\begin{array}{c}\text { Ведущая форма мировоззрения } \\
\text { (Н.С. Розов) }\end{array}$} & $\begin{array}{c}\text { Основные приоритеты } \\
\text { (автор) }\end{array}$ \\
\hline $\begin{array}{c}\text { Мифологическое } \\
\text { Сакральный порядок и правильное } \\
\text { поведение }\end{array}$ & Природа - род -с емья \\
\hline $\begin{array}{l}\text { Белигиозное } \\
\text { Божья воля и служение ей, повсеместное } \\
\text { распространение богоугдной власти }\end{array}$ & Религия - общество - семья \\
\hline $\begin{array}{l}\text { Идеологическое } \\
\text { Победа над противником, рост } \\
\text { и социальный прогресс с помощью } \\
\text { научного знания о мире }\end{array}$ & Общество - идеология - семья \\
\hline $\begin{array}{l}\text { Ценностное } \\
\text { Общность всех членов сообщества на } \\
\text { основе единства для всех сакрального } \\
\text { порядка, норм богоугодного порядка, } \\
\text { ценностей социального престижа } \\
\text { и прибыли }\end{array}$ & Индивид - общество - семья \\
\hline
\end{tabular}

Можно говорить о взаимовлиянии объективных и субъективных факторов на становление мировоззренческих основ хакасского этносообщества в тот или иной промежуток времени. В период доминирования мифологического и религиозного мировоззрений существенное влияние на динамику оказывают ряд объективных факторов - экономико-культурная основа, политическое положение на международной арене. В коллективистском обществе отмечается влияние и субъективных факторов - внутрисемейная политика, демографическое поведение, институт брака, семейное образование, семейственность занятий, семейно-родовое страхование, почитание предков.

Смена ценностей внешне проявляется в динамике структуры, состава, полоролевых позиций членов, функций семьи. Явное различие можно уловить при переходе от коллективистского к индивидуалистскому обществу [6], где под коллективистским социумом рассматривается хакасский этнос с тремя первыми мировоззренческими основаниями. В коллективистском обществе типология семьи основана на внутренних различиях внешне монолитного сообщества, разнящаяся в экономическом плане. Она отличается от типологии семьи индивидуалистского толка, где индивидуалистское основание сочетается с четвертой формой мировоззрения (табл. 2). 
При определенных условиях в этносообществе одна из основ становится преобладающей над иными нормами поведения. Можно выделить основы в зависимости от носителей этих норм, оказывающие влияние на хакасское сообщество (рис. 1). Данные основы сочетаются с четырехчленным делением мировоззренческих оснований и доминирующими ценностными категориями этносообщества.

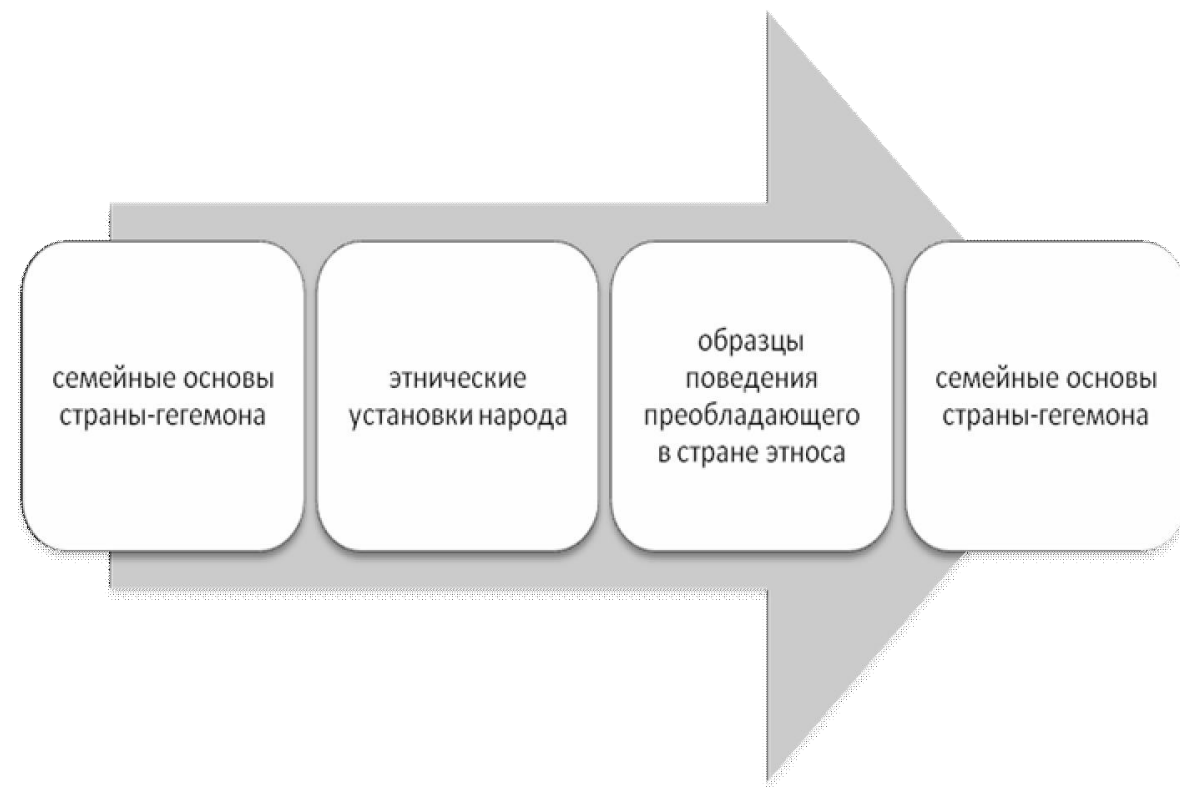

Рис. 1. Изменение семейных основ хакасов в зависимости от их носителей Correspondence of worldview forms and the main priorities of the khakass society

Эти основы имеют различную направленность. Общепринято выделять западную и восточную ориентации общества. Если изначально хакасская семья была ориентирована на восток (III до н.э. - IX в. н.э.), обогащаясь образцами семейного поведения преимущественно с китайской формой семейного устройства, то в последующем, обретя самостоятельность, она до конца сформировала и развила собственную культурную нишу с характерными для нее традициями и обычаями (IX-XIII вв.), наложившими отпечаток на современный семейный уклад. Далее ориентация семьи меняется в западном направлении с характерной европейской моделью поведения (XIV - нач. XXI в.). Сейчас заметно балансирование между сохранением и трансляцией существующих этно- и государственных культурных основ и «наплывшими» новыми нравственно-этическими установками хакасской семьи.

Стоит отметить, что ориентация хакасской семьи на восток, или восточный тип семейного поведения, в целом характерна для двух первых мировоззренческих основ, она ставит во главу угла приоритет коллективного над индивидуальным сознанием. В основе западной ориентации лежат противоположные установки, сочетающиеся в большинстве своем с двумя последними формами мировоззрения.

Дифференциация хакасской семьи в зависимости от коллективистской или индивидуалистской ориентации разнится по ряду показателей: типу супружества (моногамная, но не исключающая полигамию/моногамная, допускающая раз- 
вод); по составу семьи (расширенная/нуклеарная); по наличию детей (многодетная/малодетная); по распределению власти (патриархальная/эгалитарная); по составу семьи (полная/неполная), по полу супругов (разнополая/разнополая); по степени социальной однородности (гомогенная/гетерогенная); по месту жительства (патрилокальные/неолокальные); по типу расселения (сельская/сельская).

На основе изучения форм мировоззрения, ценностных ориентаций общества можно уловить особенности динамики хакасской семьи (табл. 2).

Таблица 2

Соответствие форм мировоззрений и иных основ хакасского общества/семьи Correspondence of worldview forms and other foundations of the khakass society/family

\begin{tabular}{|c|c|c|c|}
\hline $\begin{array}{c}\text { Ведущая форма } \\
\text { мировоззрения } \\
\text { (Н.С. Розов) }\end{array}$ & $\begin{array}{l}\text { Основы социу- } \\
\text { ма в зависимо- } \\
\text { сти от носите- } \\
\text { лей (автор) }\end{array}$ & $\begin{array}{c}\text { Ориентация общест- } \\
\text { ва (автор) }\end{array}$ & $\begin{array}{l}\text { Типы хакасской } \\
\text { семьи (автор) }\end{array}$ \\
\hline $\begin{array}{l}\text { Мифологичес- } \\
\text { кое - } \\
\text { сакральный поря- } \\
\text { док и правильное } \\
\text { поведение }\end{array}$ & $\begin{array}{l}\text { Семейные осно- } \\
\text { вы страны- } \\
\text { гегемона }\end{array}$ & $\begin{array}{l}\text { Ориентация хакас- } \\
\text { ской семьи в восточ- } \\
\text { ном направлении/ } \\
\text { формирование осо- } \\
\text { бенностей форм ха- } \\
\text { касской семьи, основ } \\
\text { семейной культуры } \\
\end{array}$ & Коллективистский \\
\hline $\begin{array}{l}\text { Религиозное - } \\
\text { божья воля и слу- } \\
\text { жение ей, повсе- } \\
\text { местное распро- } \\
\text { странение } \\
\text { богоугодной вла- } \\
\text { сти }\end{array}$ & $\begin{array}{l}\text { Этнические } \\
\text { установки наро- } \\
\text { да }\end{array}$ & $\begin{array}{l}\text { Ориентация хакас- } \\
\text { ской семьи в восточ- } \\
\text { ном направлении/ } \\
\text { формирование осо- } \\
\text { бенностей форм ха- } \\
\text { касской семьи, основ } \\
\text { семейной культуры }\end{array}$ & Коллективистский \\
\hline $\begin{array}{l}\text { Идеологическое - } \\
\text { победа над про- } \\
\text { тивником, рост и } \\
\text { социальный про- } \\
\text { гресс с помощью } \\
\text { научного знания о } \\
\text { мире }\end{array}$ & $\begin{array}{l}\text { Образцы пове- } \\
\text { дения преобла- } \\
\text { дающего в } \\
\text { стране этноса }\end{array}$ & $\begin{array}{l}\text { Формирование осо- } \\
\text { бенностей форм ха- } \\
\text { касской семьи, основ } \\
\text { семейной культуры/ } \\
\text { ориентация хакас- } \\
\text { ской семьи в запад- } \\
\text { ном направлении }\end{array}$ & $\begin{array}{l}\text { Коллективистско- } \\
\text { индивидуалист- } \\
\text { ский }\end{array}$ \\
\hline $\begin{array}{l}\text { Ценностное - } \\
\text { общность всех } \\
\text { членов сообщест- } \\
\text { ва на основе един- } \\
\text { ства для всех са- } \\
\text { крального } \\
\text { порядка, норм } \\
\text { богоугодного по- } \\
\text { рядка, ценностей } \\
\text { социального пре- } \\
\text { стижа и прибыли }\end{array}$ & $\begin{array}{l}\text { Семейные осно- } \\
\text { вы страны- } \\
\text { гегемона }\end{array}$ & $\begin{array}{l}\text { Ориентация хакас- } \\
\text { ской семьи в запад- } \\
\text { ном направлении }\end{array}$ & $\begin{array}{l}\text { Индивидуалист- } \\
\text { ско- } \\
\text { коллективистский }\end{array}$ \\
\hline
\end{tabular}

В соответствии с членением форм мировоззрений и ориентаций хакасского общества меняются типы хакасской семьи.

К вопросу о типологии семьи. Стоит отметить, что наличествуют две типологии семьи с различными основами - культурно-исторической и экономическо-социальной. В соответствии с иной типологией семьи, ос- 
нованной на политико-экономических и социальных началах, за основу исследований социального института принимается маркер дохода, который сменяет ранее существовавший классовый или социально-профессиональный критерий. Если типология хакасской семьи с культурноисторической основой исходит из изучения хакасской семьи в разрезе рабочей, крестьянской, служащей, то в соответствии со второй - на первый план выступают маргинальные, кризисные, благополучные и процветающие семьи. Современная типология, основанная на уровне дохода семьи, является результатом исследований М.С. Мацковского [4], которые дополняют сложившуюся ныне концепцию о семье как экономической единице.

В период господства коллективистской семьи официально рассматривалась позиция социальной организации, где категория «родство» считалась основополагающей. Основным разработчиком данного направления является А.Г. Харчев [7]. В современное время акцент делается на экономической основе семьи с понятиями «хозяйство» и «совместный бюджет». Смещение акцентов происходит в результате смены экономического режима страны и перехода от бюджетной к бюджетно-рыночной модели, в результате чего семья понимается единицей экономических структур. В реальности российскую семью сложно признать полноправным элементом экономики в таком понимании, которое сложилось в ряде стран, например в Китае, где она представляет собой развитую сеть бизнес-ячеек общества, в связи с отсутствием полного и широкого цикла семейного производства с выстроенной сетью реализации товаров, налоговой базы для семейно-родственных бизнескорпораций.

Представленная в табл. 2 типология хакасской семьи рассматривается в логическом соответствии с доминирующими типами этносообщества как исторический переход от одного к другому типу хакасской семьи - типология с культурно-исторической основой (рис. 1). Переходные типы хакасских семей или семьи промежуточного типа сочетают в себе некоторые элементы обоих образцов поведения.

Промежуточный тип хакасской семьи являет собой неоднородную структуру. Можно отметить несколько элементов в зависимости от количества проявлений:

1) семьи с маловыраженным переходным типом;

2) семьи с умеренно выраженным переходным типом;

3) семьи с явно выраженным переходным типом.

Каковы критерии переходных типов семьи? Если одна из характеристик удовлетворяет типу семьи коллективистского толка, то ее уже можно отнести к первой категории; если количество маркеров достигает половины, то следует говорить о семье второго уровня; иные относятся к третьей категории с ярко выраженным состоянием.

В результате деления хакасских семей по территориальному признаку, национальному состоянию в браке, экономическому и религиозному положению можно уловить особенности переходных типов хакасской семьи (табл. 3). 
Переходные периоды хакасской семьи

Transition periods of a khakass family

\begin{tabular}{|c|c|c|}
\hline $\begin{array}{c}\text { Семья с маловыраженным } \\
\text { переходным типом }\end{array}$ & $\begin{array}{c}\text { Семья с умеренно выра- } \\
\text { женным переходным } \\
\text { типом }\end{array}$ & $\begin{array}{l}\text { Семья с явно выражен- } \\
\text { ным переходным типом }\end{array}$ \\
\hline \multicolumn{3}{|c|}{ Территориальный признак } \\
\hline Сельские семьи & $\begin{array}{l}\text { Семьи, располагающиеся } \\
\text { вблизи городских цен- } \\
\text { тров, в т.ч. и пгт }\end{array}$ & Городские семьи \\
\hline \multicolumn{3}{|c|}{ Национальное состояние в браке } \\
\hline $\begin{array}{l}\text { Разнонациональные се- } \\
\text { мьи, в которых член се- } \\
\text { мьи принадлежат к этни- } \\
\text { ческой группе азиатского } \\
\text { типа (внутренние и внеш- } \\
\text { ние мигранты). } \\
\text { Однонациональные ха- } \\
\text { касские семьи, в которых } \\
\text { супруги являются «вы- } \\
\text { ходцами» из сельской } \\
\text { местности }\end{array}$ & $\begin{array}{l}\text { Однонациональные се- } \\
\text { мьи, в которых супруги } \\
\text { являются представителя- } \\
\text { ми титульного этноса. } \\
\text { Преимущественно «вы- } \\
\text { ходцы» из смешанных } \\
\text { городских и сельских } \\
\text { территорий, а также од- } \\
\text { нородных - соединяю- } \\
\text { щих в себе представите- } \\
\text { лей жителей городских } \\
\text { центров }\end{array}$ & $\begin{array}{l}\text { Разнонациональные се- } \\
\text { мьи, представляющие } \\
\text { собой единство хакасско- } \\
\text { го и этнических групп } \\
\text { европеоидного типа. }\end{array}$ \\
\hline \multicolumn{3}{|c|}{ Религиозное состояние } \\
\hline $\begin{array}{l}\text { Семьи, где глубоко верует } \\
\text { один из членов семьи. } \\
\text { Одноверцы }\end{array}$ & $\begin{array}{l}\text { Семьи, «верующие от } \\
\text { случаю к случаю». Сюда } \\
\text { относятся семьи с двое- } \\
\text { верной основой - христи- } \\
\text { анско-шаманистского } \\
\text { толка }\end{array}$ & $\begin{array}{l}\text { Семьи, относящие себя к } \\
\text { категории неверующих }\end{array}$ \\
\hline \multicolumn{3}{|c|}{ Экономическое положение } \\
\hline $\begin{array}{l}\text { Семьи, чье материальное } \\
\text { положение, как правило, } \\
\text { является сложным }\end{array}$ & $\begin{array}{l}\text { Семьи со средним дос- } \\
\text { татком }\end{array}$ & $\begin{array}{l}\text { Семьи с высоким достат- } \\
\text { ком }\end{array}$ \\
\hline
\end{tabular}

Сравнивая различные позиции хакасской семьи, отмечаем доминирование показателей первой колонки при включении элементов второго типа, т.е. преобладающей является семья с умеренно выраженным переходным типом.

Адаптация выделенных типов хакасской семьи в изменяющихся, кризисных условиях будет выше у семьи с маловыраженным переходным типом, сложнее придётся семьям 2-го и 3-го типов. В изменяющихся экономических условиях, в частности кризисных, хакасская городская семья становится более уязвимой и зависимой от сельской семьи, являющейся «производителем» продукции первой необходимости. Кроме того, в сложных условиях весьма значимой становится поддержка родственников близкого и дальнего круга, которая сохраняется в лоне подобного типа семьи, нежели у семей обособленного типа. В результате в условиях экономических потрясений перенести невзгоды окажется проще семьям с более выраженными коллективистскими основами. 
Социальные преобразования, связанные с расширением структуры и ее институтов, приводят к переменам, усугубляющим положение всех типов семьи. В результате разрастающейся сети социальных институтов усиливается психофизиологический дискомфорт семьи. Катастрофическая нехватка времени, возникающая в результате взаимодействия членов семьи с социальными институтами, приводит к ощущению второстепенности семьи в сравнении с иными социальными структурами. В условиях больших потрясений, как правило, происходит сужение социальной «паутины», что, с одной стороны, отрицательно сказывается на семье в связи с сильной зависимостью ее структурных элементов, с другой - дает положительный эффект по причине появления ощущения свободы, достатка времени. Дискомфорт в хакасских семьях проявляется по-разному в зависимости от места проживания. Он более выражен в урбанизированных центрах в связи с наличием расширенной сети социальных структур.

Используя наработки типологического подхода $c$ политикоэкономическим и социальным началами, совмещаем их с выделенными тремя переходными типами современной хакасской семьи (табл. 4).

Типы современной хакасской семьи*

Таблий 4

Types of a modern khakass family*

\begin{tabular}{|c|c|c|c|c|}
\hline $\begin{array}{c}\text { Переходные типы } \\
\text { семьи }\end{array}$ & $\begin{array}{c}\text { Процветаю- } \\
\text { щие }\end{array}$ & $\begin{array}{c}\text { Благополуч- } \\
\text { ные }\end{array}$ & Кризисные & $\begin{array}{c}\text { Маргиналь- } \\
\text { ные }\end{array}$ \\
\hline $\begin{array}{l}\text { Семья с маловы- } \\
\text { раженным пере- } \\
\text { ходным типом } \\
\text { (сельчане, одно- } \\
\text { национальные, } \\
\text { одноверцы) }\end{array}$ & - & $\begin{array}{l}\text { Минимальная } \\
\text { доля }\end{array}$ & $\begin{array}{l}\text { Преимуще- } \\
\text { ственная } \\
\text { доля }\end{array}$ & $\begin{array}{l}\text { Значительная } \\
\text { доля }\end{array}$ \\
\hline $\begin{array}{l}\text { Семья с умеренно } \\
\text { выраженным пе- } \\
\text { реходным типом } \\
\text { (население вблизи } \\
\text { городских цен- } \\
\text { тров, однонацио- } \\
\text { нальные, двоевер- } \\
\text { цы) }\end{array}$ & $\begin{array}{l}\text { Минимальная } \\
\text { доля }\end{array}$ & $\begin{array}{l}\text { Незначитель- } \\
\text { ная доля }\end{array}$ & $\begin{array}{l}\text { Преимуще- } \\
\text { ственная } \\
\text { доля }\end{array}$ & $\begin{array}{l}\text { Незначитель- } \\
\text { ная доля }\end{array}$ \\
\hline $\begin{array}{l}\text { Семья с явно вы- } \\
\text { раженным пере- } \\
\text { ходным типом } \\
\text { (горожане, разно- } \\
\text { национальные, } \\
\text { неверующие) }\end{array}$ & $\begin{array}{l}\text { Максималь- } \\
\text { ная доля }\end{array}$ & $\begin{array}{l}\text { Преимущест- } \\
\text { венная доля }\end{array}$ & $\begin{array}{l}\text { Незначи- } \\
\text { тельная доля }\end{array}$ & $\begin{array}{l}\text { Предполо- } \\
\text { жительно } \\
\text { значительная } \\
\text { доля }\end{array}$ \\
\hline
\end{tabular}

* Ранжирование по группам для сравнения семей внутри одной этнической группы.

В категорию процветающей хакасской семьи вошли семьи, чьи доходы позволяют приобретать дорогостоящие вещи, не отказывая себе во многом, а также имеющие возможность реализовывать все виды платных услуг. Такие семьи характеризуются более благоприятными условиями для воспитания и образования подрастающего поколения. В их число входит большинство столичных хакасских семей в активном трудовом возрасте 
35 лет и старше. Процент таких семей, по предварительным данным ${ }^{1}$, варьируется от 5 до 10 единиц.

К благополучным причисляются семьи, где уровень совокупного дохода составляет 50-70 \% от среднего показателя по региону. Они являются перспективными в плане самостоятельного решения возникающих внутрисемейных проблем. Это большинство семей в возрасте от 35 лет и старше. Их доля постоянно колеблется в сторону ее снижения с 20 до $15 \%$.

К типу кризисной семьи относятся семьи, находящиеся ниже черты бедности. Они характеризуются проблемами в отношениях между ее членами, в воспитании детей. Решение проблем в большей части возложено на государство. Это преимущественно неполные, «молодые» и «старые» семьи, а также «стареющие» семьи одиночек, у которых пенсия является низкодоходным и единственным финансовым источником. На сегодняшний день данный тип хакасской семьи является преобладающим. Он расширяется в результате прогрессирующего роста уровня безработицы.

Маргинальные семьи являются сложной категорией семей с крайне низкими доходами, которые обусловлены различными факторами - склонностью ее членов к употреблению алкогольных и наркотических веществ, плохими жилищными условиями или отсутствием жилья, тюремным заключением, болезнью, иждивенческими настроениями. Эту категорию «наполняют» хакасские семьи, состоящие из одного человека, семьи молодежных возрастов, в частности лиц 1980-1990-х годов рождения. Данный тип семьи, по неполным данным, составляет 3-5 \% от общего количества хакасских семей, велика вероятность его количественного расширения.

С очевидностью, в изменяющихся условиях адаптация пройдет успешно у первых двух типов хакасских семей, иные окажутся в сложном положении. Вопрос о физическом и нравственном состоянии последних станет ключевым направлением социальной работы.

Таким образом, хакасская семья вовлечена в процесс динамики социального института. Изменение культурных основ, моделей поведения общества в современный переходный период отразилось на смене преобладающих культурно-исторических типов семьи - от коллективистского к коллективистскоиндивидуалистскому толку. Возникающие переходные типы семьи в этносообществе приводят к обогащению общего банка типов семьи. Доминирование на сегодняшний момент кризисной хакасской семьи с умеренно выраженным переходным типом позволяет говорить о ее низком уровне адаптации к современным реалиям. Динамика этнокультурных основ приводит к смене типов семей, расширению объема внешних связей и сужению внутренней структуры семьи.

В целом существует необходимость в изменении и внесении точных корректировок в общепринятые семейные типологии с учетом этнических особенностей, что связано с потребностью в упорядочении разнородных объектов и оказании мер государственной поддержки, контроле состояния семьи в различных регионах РФ.

\footnotetext{
${ }^{1}$ Социологическое исследование автора по теме: «Хакасская семья» (2014-2016 гг.). Выборочная совокупность респондентов - 600 единиц. Выборка: совмещенная стратифицированная территориальная (квоты по полу, возрасту, уровню образования).
} 


\section{Литература}

1. Тугаринов В.П. О ценностях жизни и культуры. Л.: Изд-во ЛГУ, 1960. 156 с.

2. Дробниикий О.Г. Проблемы нравственности. М.: Наука, 1977. 333 с.

3. Ивнин А.А. Апокалипсис любви. Философское эссе. М., 2012. 296 с.

4. Мацуковский М.С. Российская семья в изменяющемся мире // Семья России. 1995. № 3-4. C. $32-34$.

5. Розов Н.С. Ценности в проблемном мире: философские основания и социальные приложения конструктивной аксиологии. Новосибирск: Изд-во Новосиб. ун-та, 1998. С. 16-38.

6. Чуринов Н.M. Коллективизм и индивидуализм и их теоретизирование в западной традиции // Теория и история. 2003. № 3. С. 42-55.

7. Харчев А.Г. Брак и семья в СССР. Опыт социологического исследования. М.: Мысль, 1979. C. 367.

8. Николаев Н.Н. Типы семей в современном российском обществе: социальнофилософский анализ : автореф. дис. ... канд. филос. наук. Ростов н/Д, 2007. 21 с.

Troshkina Irina N. Khakass Research Institute of Language, Literature and History (Abakan, Russian Federation)

E-mail: i.troschkina2012@yandex.ru

DOI: $10.17223 / 1998863$ X/№35/№ 10

DYNAMICS OF VALUE ORIENTATIONS AND TYPES OF A FAMILY (ON THE EXAMPLE OF THE KHAKASS ETHNOS)

Key words: value orientations, typology of the Khakass family.

\section{References}

1. 1. Tugarinov, V.P. (1960) O tsennostyakh zhizni $i$ kul'tury [On values of life and culture]. Leningrad: Leningrad State University.

2. Drobnitsky, O.G. (1977) Problemy nravstvennosti [Issues of morality]. Moscow: Nauka.

3. Ivnin, A.A. (2012) Apokalipsis lyubvi. Filosofskoe esse [Love apocalypse. A philosophical essay]. Moscow: Direkt-Media.

4. Matskovsky, M.S. (1995) Rossiyskaya sem'ya v izmenyayushchemsya mire [The Russian family in a changing world]. Sem'ya Rossii. 3-4. pp. 32-34.

5. Rozov, N.S. (1998) Tsennosti v problemnom mire: filosofskie osnovaniya $i$ sotsial'nye prilozheniya konstruktivnoy aksiologii [Values in the troubled world: Philosophical foundations and social applications of constructive axiology]. Novosibirsk: Novosibirsk State University.

6. Churinov, N.M. (2003) Kollektivizm i individualizm i ikh teoretizirovanie v zapadnoy traditsii [Collectivism and individualism and their theorizing in Western tradition]. Teoriya $i$ istoriya. 3. pp. $42-55$.

7. Kharchev, A.G. (1979) Brak i sem'ya v SSSR. Opyt sotsiologicheskogo issledovaniya [Marriage and family in the Soviet Union. The sociological research]. Moscow: Mysl'.

8. Nikolaev, N.N. (2007) Tipy semey v sovremennom rossiyskom obshchestve: sotsial'nofilosofskiy analiz. [Types of families in modern Russian society: The social and philosophical analysis]. Abstract of Philosophy Cand. Diss. Rostov-on-Don. 